\title{
A Prototype Analysis of Virtue
}

Liz Gulliford ${ }^{1}$, Blaire Morgan ${ }^{2}$ \& Karen Jordan ${ }^{3}$

\footnotetext{
${ }^{1}$ Correspondence regarding this article should be addressed to Liz Gulliford, University of Northampton, UK, Liz.Gulliford@Northampton.ac.uk

${ }^{2}$ School of Psychology, University of Worcester, UK

${ }^{3}$ School of Education, University of Iceland, Iceland
} 


\begin{abstract}
The question of how ordinary people understand the concept of virtue is under-scrutinized. The current study highlights incongruities between strengths of the VIA-IS and features 'laypeople' instinctively associate with virtue. In Study 1 we examined freely-listed features associated with virtue in 189 participants $(20-81$ years). In Study $2(\mathrm{~N}=205,18-84$ years $)$ we found features of 'virtue' which overlapped with 'good character' and 'moral persons', in addition to features uniquely associated with 'virtue'. Studies $3 \mathrm{a}$ and $3 \mathrm{~b}(\mathrm{~N}=105,18-73$ years) partially corroborated the prototypical structure of virtue, however, demonstrated some inconsistencies in perceptions of virtue-features. Given lay understandings of virtue can be at odds with academic frameworks, this stresses the importance of definitions and guidance when measuring virtue concepts. The current studies signal future research avenues; cross-cultural and qualitative examinations of lay conceptions of virtue, and the possibility of developing new measures and frameworks informed by lay conceptions.
\end{abstract}

\title{
Key Words
}

Virtue, character strengths, VIA-IS, prototype analysis, moral

\section{Introduction}

Recently there has been renewed academic interest in character strengths and virtues. However, the question remains whether nonprofessional understandings of virtue reflect scholarly conceptions. The present study offers insight into laypeople's conceptions of virtue and how this compares with the VIA classification (Peterson \& Seligman, 2004), the dominant approach to strengths and virtues within positive psychology. It references Ruch and Proyer's 
(2015) mapping of the VIA strengths into the six virtue categories, and compares 'virtue' with existing examinations of 'highly moral persons' (Walker \& Pitts, 1998) and 'good character' (Lapsley \& Lasky, 2001).

Has the word 'virtue' lost traction in the modern world (Kesebir \& Kesebir, 2012)? One way to illuminate this question (used in the current study) is to adopt the approach of prototype analysis, the first step of which is to ask laypeople what features they believe characterise a given concept (in this case, 'virtue').

It will be appreciated that the 'bottom-up' free listing task used here, the first stage of the method of prototype analysis, yields a spontaneous assessment of features associated with virtue, and the degree to which the virtues instinctively named by non-professionals compare with the strengths and virtues positive psychologists have deemed worthy of inclusion in the VIA (which remains the leading classification of strengths and virtues currently in use). ${ }^{4}$ This is in contrast to Ruch and Proyer (2015), who took the existence of the twenty four strengths of the VIA as read, requiring participants to map these strengths onto the six superordinate virtues of the classification. That is, whilst Ruch and Proyer asked participants to work within the parameters of the VIA, the current study incorporates free listing of virtue features. Participants were given a blank slate onto which they spontaneously inscribed features of virtue; thus tapping into a lay understanding, unmediated by existing models of virtue.

It should be noted at this juncture, that Peterson and Seligman (2004) used the concept of virtue in a highly specific way. They defined virtues as superordinate categories within the VIA classification that are exemplified by subordinate 'character strengths'. They identified six superordinate virtue categories: wisdom, courage, humanity, justice, transcendence and

\footnotetext{
${ }^{4}$ Cawley, Martin \& Johnson (2000) developed the Virtues Scale, a 140-item self-report measure of virtues created using the lexical tradition (Brokken, 1978). Though this preceded the VIA-IS, the measure has been little used and has effectively been superseded by the much-popularised VIA-IS.
} 
temperance. Peterson and Seligman (2004) proposed that these six virtues are operationalised through the twenty-four character strengths of the VIA-IS. However, this 'two-level' conception of how character strengths relate to virtues could be disputed by both 'experts' (philosophers or psychologists) and by laypeople, on the grounds that there is substantial overlap in the meaning of 'character strengths' and 'virtues' in ordinary language. The understanding of character strengths as embodying 'routes to the virtues' is therefore specific and idiosyncratic to the VIA-IS.

In any event, factor analyses of the VIA-IS have failed to confirm a six-factor solution in support of the superordinate virtue categories described above. While McGrath and Walker (2016) suggested a four-factor solution in youths aged 10-17, McGrath (2015) identified three virtue factors in the VIA-IS (caring, inquisitiveness and self-control) - a finding corroborated more recently by McGrath, Greenberg and Hall-Simmonds (2018). Thus, even when the VIA character strengths are taken to be definitive, the precise loadings of individual character strengths onto overarching virtue categories can be disputed.

\section{Virtue and Virtue Ethics}

Interest in virtue has been growing in moral philosophy, education and psychology. A virtue is a trait, disposition or quality deemed to be morally good. Virtues are valued because they contribute to an individual's own moral good and, by extension, the good of society (Annas 2011; Kristjánsson, 2015). There has been a corresponding interest in 'virtue ethics' (Annas, 2011; MacIntyre, 1981). A virtue ethicist focuses less on moral behaviour, viewed in isolation, and more on the moral character of individuals, whose thinking, feeling, motivation and action is permeated by the virtues they embody. Whether it is deemed morally acceptable to lie or steal depends not on a universal law or on its overall pro-social consequences (as the moral 
theories of deontology or consequentialism assume), but on whether an individual acted from the virtues they exemplify.

As noted, Peterson and Seligman's (2004) VIA classification encompasses twenty-four 'character strengths' which are 'the psychological ingredients - processes or mechanisms that define the virtues' (Peterson \& Seligman, p. 13). As we saw, within the VIA-IS there are six overarching virtues (wisdom and knowledge, courage, humanity, justice, temperance and transcendence). Ruch and Proyer (2015) asked 70 experts and 41 laypeople to rate how prototypical each of the previously identified character strengths are for each of the six virtues. They thus sought an alternative means of assigning strengths to superordinate virtue categories than factor analysis, the method adopted by McGrath (2015), McGrath \& Walker (2016) and McGrath, Greenberg and Hall-Simmonds (2018). It will be appreciated that Ruch and Proyer (2015) assumed the existence of the twenty-four character strengths of the VIA-IS; what they sought to examine was whether each of the twenty-four strengths were accurately categorised within the six superordinate virtue types.

Despite, the growing prominence of the concept of virtue in psychology (Damon \& Colby, 2015; Fowers, 2005), there has been relatively little examination of what this concept means to the general public. This study, using prototype analysis, elucidates lay understandings of virtue by spontaneously eliciting virtues and virtue features from nonprofessional people. It departs substantially, therefore, from the factor analyses of the VIA-IS and from Ruch and Proyer's (2015) study mapping the character strengths to superordinate virtue categories.

Prototype analysis has been applied to a range of concepts and, importantly for the current study, those include 'moral persons' (Hardy, Walker, Olsen, Skalski \& Basinger, 2011; Walker 
\& Pitts, 1998) and 'good character' (Lapsley \& Lasky, 2001). ${ }^{5}$ A prototype study of virtue complements existing prototype analyses of these allied concepts, enabling the unique features of virtue and its degree of overlap with these concepts to be examined.

\section{Prototype Analysis}

Rosch (1977) found that people tend to categorize many concepts based on how closely they map onto prototypical exemplars of a category. ${ }^{6}$ Within the category 'fruit', an apple would be deemed more representative (i.e. prototypical) than an olive, which is more removed from the most prototypical examples, and shares fewer family resemblances with them. The unique taste of an olive does not match the prototype that most fruit is sweet, rendering an olive less prototypical of the concept of fruit than, say, a pear.

To establish a prototypical structure, it must be shown that some features of the concept are more representative or central than others. This is usually achieved by asking people to list features of a concept, which are subsequently rated for centrality/importance. This process allows a 'nucleus' of central concept features to be identified, around which comparatively peripheral, marginal and remote concept features can be classified.

To validate a prototypical structure, it must be shown that feature centrality influences cognition relating to the concept. Methods drawing on both implicit and explicit processes have been developed to this end. Implicit recognition and recall memory tasks assume that central concept features are more likely to be remembered than peripheral or remote features, indicative of feature centrality impacting cognition. While recognition memory tends to yield

\footnotetext{
${ }^{5}$ Vauclair, Wilson \& Fischer's (2014) paper on laypeople's associations of 'moral character' across four countries is also pertinent, though the cross-cultural nature of this research and its distinctive methodology make it unsuited for direct comparison with the current analysis.

${ }^{6}$ This applies to so-called open textured entities (as opposed to mathematical or logical entities which can be defined by one or more individually necessary and jointly sufficient criteria).
} 
results in the predicted direction (Fehr, 1988; Kearns \& Fincham, 2004; Lambert, Graham, \& Fincham, 2009), attempts to corroborate the prototypical structure of concepts using recall memory have performed less consistently (Fehr, 1988; Kearns \& Fincham, 2004; Lapsley \& Lasky, 2001). Thus whether a concept is found to have a prototypical structure may depend to some extent on the method, and it is not clear whether findings which fail to corroborate prototypicality are consistently reported; the so-called 'file drawer problem' (Rosenthal, 1979). Greater convergence of measures of internal structure (implicit or explicit) affords greater

confidence in establishing that a concept is prototypically organized. However, from a statistical point of view it follows that as the number of methods of corroborating prototypical structure increases, so too does the probability of finding discrepant results.

Prototype analysis makes a contribution towards defining concepts from a 'bottom-up' lay perspective (Hardy et al., 2011; Morgan et al, 2014), as opposed to circumscribing them from a 'top-down', 'expert' or 'specialist' point of view. This allows concepts to be examined without imposing a priori biases (see Walker \& Pitts, 1998, p. 404). In the current study, the concept of virtue is examined from a lay perspective - a group unfamiliar with the VIA classification and its associated (and idiosyncratic) understanding of virtues as superordinate categories embodied by specific character strengths. Using a lay sample, one could expect the six 'core' virtues of the VIA-IS to be named as central features of the concept of virtue. What is less certain is whether participants would associate all twenty-four character strengths of the VIA-IS with the concept of virtue, which one might expect, if these strengths are taken to be the 'routes' to embodying the virtues.

\section{Overview of Studies 1, 2 and 3}

The main aim of this study was to examine how people conceptualise virtue. This has 
received insufficient research attention to date, with the consequence that scholars could be projecting their own understandings of virtue (including its structural relationship to character strengths) onto nonprofessionals. In Study 1, we examined features typically associated with the concept of virtue. In Study 2, a separate group of participants rated how central the features identified in Study 1 were to the concept of virtue, and compared the degree of overlap between 'virtue' and previously examined prototypes of 'moral persons' (Walker \& Pitts, 1998) and 'good character' (Lapsley \& Lasky, 2001). Following previous research by Morgan et al (2014), we combined frequency scores (from Study 1) with centrality scores (from Study 2) to create a combined 'sum of ranks' metric. ${ }^{7}$ This was used in Study 3 a to examine how centrality and frequency of features affected people's assessments of whether a fictitious character was deemed virtuous, and in Study 3b, where a recognition task was used to see whether participants falsely recognized more central than peripheral features of virtue.

\section{Study 1}

In Study 1 participants listed the features they believed exemplified the concept of virtue, rating the valence of each feature using a 5 -point Likert scale $(1=$ very negative to $5=$ very positive).

\section{Method}

\section{Participants}

One-hundred-and-eighty-nine adults participated via an online survey. Participants were recruited via a crowdsourcing website and were paid $£ 1.00$ in return for participation. All

\footnotetext{
${ }^{7}$ To strike a balance between the more instantaneous responses of Study 1 and the more considered judgements of Study 2.
} 
participants were UK citizens. Of the sample, $49.7 \%$ of participants were female. Ages ranged from $20-81$ years $(M=47$ years $)$. Eighty-nine percent were White-British. When asked about their highest qualification, 53\% reported having GCSEs, A-levels or vocational qualifications, $34 \%$ of the sample had a higher education degree and $9 \%$ had completed a postgraduate qualification. Fifty percent of the sample was Christian and 36\% were Atheist or Agnostic. Of those who identified with a religion, $22 \%$ indicated that they practiced it.

\section{Design and Procedure}

Participants were instructed to list the features and characteristics they think typify the concept of virtue. Instructions were adapted from Fehr and Russell (1984) and Morgan et al. (2014):

"We are exploring what characteristics and attributes people think of when they hear the word virtue. For example, if you were asked to list the characteristics of the concept of gratitude you might write "thankful", "appreciation", "expressing thanks", "feel guilty”, “crying”, “obligation to return favour" and so on. Here we would like you to list the features and characteristics that you think are typical of the concept of virtue. We would like to know what you understand by the term virtue, what features/characteristics you believe exemplify a virtuous act or virtuous person.

It may help to think about this task as if you are explaining the word virtue to someone who has never heard the term before. So think about what virtue is and the actions, emotions, thoughts and feelings that are involved. We are interested in any positive or negative attributes of virtue; therefore we would like you to also rate the positivity or negativity of each feature you come up with on the scale provided."

Participants rated the valence of their self-generated features using a 5-point Likert scale $(1=$ very negative to $5=$ very positive); this was done in parallel with feature generation. The survey took an average of 7 minutes to complete. 


\section{Results and Discussion}

A complete list of 1407 virtue features was generated ( $M=8$ features). These were grouped by linguistic and semantic similarity (see Fehr, 1988; Rosenberg \& Sedlak, 1972) and subsequently coded into larger categories by two independent raters. Items sharing word roots were categorized together, for example 'charity' and 'charitable'. Next, the raters evaluated features based on semantic meaning; features with similar meanings were placed in the same category. For example, 'brave' and 'courageous' were combined. Responses containing more than one feature were counted as multiple features.

In preparation for assessing the level of agreement in coding, the two raters established the features for analysis. Disagreements were resolved by a third researcher. This resulted in 127 virtue features. Of these, 28 were named by only one or two respondents and were discarded, leaving 99 key virtue features (see Table 1). As is usual practice in prototype analyses, agreement between the raters was assessed with Cohen's Kappa $(K=0.95)$.

Participants identified 99 key virtue features. They recognised general features, such as 'good/goodness' (46\%), 'moral/morality' (42\%), and 'ethical' (12\%). They also named specific virtues such as 'honesty/truthfulness' (48\%) and 'trust/trustworthy' (17\%). Participants named some - but not all - of the 'character strengths' from the VIA classification as features of virtue (see Table 2).

Notably, participants rated most virtue features positively $(\mathrm{M}=4.16, \mathrm{SD}=0.66)$. Only four features were assigned a negative valence: 'smug/smugness', 'self-righteous' 'arrogant/boastful', and 'gullible', though these were referenced infrequently (see Table 1). As Table 2 clearly shows, fourteen out of the twenty-four character strengths of the VIA were mentioned in our sample, it should be noted, however, that eight of these character strengths were identified by less than $5 \%$ of the sample. 
The VIA character strengths of 'creativity', 'curiosity', 'judgement', 'love of learning', 'perspective', 'zest', 'social intelligence', 'teamwork', 'leadership' and 'appreciation of beauty' did not feature in the sample. These strengths, said to 'exemplify' superordinate virtues of the VIA, were not mentioned. Within the category of wisdom, none of the five VIA 'character strengths' ('creativity', 'curiosity', 'judgement', 'love of learning' and 'perspective') were named as features, which one might have expected if laypeople see these strengths as being typical examples ('exemplifications') of the virtue of wisdom. The same applies to 'social intelligence' manifesting the virtue of humanity and 'teamwork' and 'leadership' exhibiting the virtue of justice.

The higher-order VIA virtue categories of 'humanity', 'temperance' and 'transcendence' were not named in this sample (see Table 1). This suggests that participants in our sample did not associate 'humanity', 'transcendence' and 'temperance' with virtue. This raises the question of whether to some extent, these more specialist virtue terms have limited utility in the general population, though it must be acknowledged that a different sample might deem these features of virtue in a replication.

The free-listing task used here can be contrasted with the approach of Ruch and Proyer (2015), who took the existence of the character strengths of the VIA for granted, and asked participants only to re-categorise these strengths into the six superordinate virtue categories. Findings from the current study call into question whether these character strengths (and indeed the superordinate virtue categories of the VIA) are named instinctively by laypeople. On this basis, it seems plausible to suggest that some categories of the VIA classification may not adequately reflect a lay view, and that the classification could be overdetermined by a priori assessments of what 'experts' consider representative of both subordinate 'character strengths' and superordinate virtue categories. 


\section{Study 2}

Study 2 assessed the centrality (importance) of the virtue features from Study 1. We presented participants with the 99 key virtue features and examined the degree to which centrality ratings of features converged across participants. If the concept of virtue has a prototypical structure, respondents should largely agree on which features are central.

\section{Method}

\section{Participants}

Two-hundred-and-five adults participated via an online survey. Participants were recruited via a crowdsourcing website and were paid $£ 1.50$ in return for participation. All participants were UK citizens. Participants from Study 1 were excluded from participation. Of the sample, $55 \%$ of participants were female, $94 \%$ were White-British and ages ranged from $18-84$ years $(\mathrm{M}=47$ years). Regarding participants' highest qualification, 50\% reported having GCSEs, Alevels or vocational qualifications, $37 \%$ of the sample had a higher education degree and $6 \%$ had completed a postgraduate qualification. In terms of religion, $51 \%$ of the sample was Christian and 36\% were Atheist or Agnostic. Of those who identified with a religion, 26\% indicated they practiced it.

\section{Design and procedure}

Participants were presented with the 99 key virtue features that emerged from Study 1. Following the next stage of the prototype analysis methodology, they were then asked to rate how central each feature was to the concept of virtue using an 8-point Likert scale $(1=$ not at 
all central to $8=$ extremely central). The survey took an average of 11 minutes. Feature order was randomized across participants.

\section{Results and Discussion}

Mean centrality ratings for all 99 key virtue features are displayed in Table 1 . To test the consistency of responses across participants, we conducted reliability tests. These tests revealed high internal consistency (intraclass correlation and $\alpha=.98$ (participants as items, features as cases)) suggesting that participants largely agreed on which features are central to virtue. Further analyses revealed a medium, significant, positive correlation between centrality scores in Study 2 and frequency scores in Study $1(\mathrm{r}=.37, \mathrm{p}<.01)$; features rated as most central in Study 2 tended to be named with greater frequency in Study 1.

Importantly, this is not the first prototype analysis conducted within the moral domain. Walker and Pitts (1998) generated prototypical ratings for 'highly moral persons' and Lapsley and Lasky (2001) explored what is typical of persons with 'good character' (see Table 3). ${ }^{8}$ When comparing features of the current analyses to the two previous analyses there is considerable overlap. Examples of features that appear in all three studies include moral values such as 'honest', 'kind(ness)', 'integrity', 'genuine', 'sincere', 'empathy', 'loyal(ty)' and 'respect', as well as adjectives such as 'law abiding', 'ethical', and 'upstanding'.

There are, however, several features that appear specific to the concept of virtue. Examples of virtue-specific features include 'excellence' and 'noble', and specific virtues, such as

\footnotetext{
${ }^{8}$ Walker \& Pitts' (1998) Canadian sample consisted of 120 people drawn equally from three age groups: 18-25 years; 35-55 years and $65-94$ years. Sixty-eight percent of the gender-balanced sample were Caucasian. Lapsley \& Lasky's (2001) American sample consisted of 121 individuals (69\% female), ranging in age from 18 $48(\mathrm{M}=21.48)$. Eight-nine percent of the predominantly undergraduate sample were white.
} 
'gratitude', 'charity', 'prudence' and 'hope'. Other unique features of virtue included 'trait/characteristic/attribute' and 'quality', mapping onto the understanding of virtues as relatively stable and consistent valued positive traits (Kristjánsson, 2015).

To examine the degree of correlation between virtue features, features of moral persons, and features of good character we conducted a bivariate correlation. Results illustrated that there was a medium positive correlation between features of virtue and moral persons $(r=.47, p<$ $.01)$ and a strong positive correlation between virtue and good character features $(r=.74, p<$ $.001)$. The correlation between features of moral persons and good character was medium and positive $(\mathrm{r}=.36, \mathrm{p}<.05)$. These results suggest there is a larger degree of overlap between virtue and good character than between either virtue and moral persons or moral persons and good character. ${ }^{9}$

The greater correspondence between virtue and good character is not surprising. Morality can be based on rules, consequences and (in the case of virtue ethics) on enduring positive dispositions. While Walker and Pitts (1998) asked participants to generate features about a moral person (rather than morality per se), it seems likely that the reference to 'moral' engendered less correspondence in features than was found between virtue and good character, both of which necessarily narrow attention towards mostly desirable human attributes, traits or qualities.

\section{Study 3a}

Study $3 \mathrm{a}$ aimed to demonstrate that feature centrality (based on the sum-of-ranks metric

\footnotetext{
${ }^{9}$ It should be noted, however, that the data from these three studies derives from three countries (USA, Canada and UK) and span almost two decades. The ideal study would compare data from one country at one time-point across these three categories.
} 
shown in Table 1) affected cognition of the concept of virtue. The sum-of-ranks metric combines a feature's rank by frequency with its rank by centrality). It will be recalled from the introduction that to validate whether a concept has a prototypical structure, it must be shown that feature centrality influences cognition relating to the concept. Explicit and implicit tasks can both be used to corroborate a concept's prototypical structure. The method used in Study 3a constituted an explicit cognitive task. We followed the procedure outlined in Study 3 of an earlier prototype analysis of gratitude (Morgan et al, 2014).

Participants were presented with 16 character descriptions (A - P). Four contained features with a high combined centrality and frequency rank (the sum-of-ranks metric) from Studies 1 and 2; these formed the 'Central' condition. Three more conditions were created by choosing 'Peripheral' features from the middle of Table 1; 'Marginal' features (from the bottom third) and 'Remote' features (those named by one or two participants in Study 1).

After reading each character description, participants answered seven questions gauging their impression of the person described. The key question was 'How VIRTUOUS is this person?' In this study one would expect fictional characters displaying more central features to be rated as more virtuous than those exhibiting less central features.

\section{Method}

\section{Participants}

One-hundred-and-five adults participated via an online survey. All participants were UK citizens and were recruited via a crowdsourcing website and were paid $£ 1.50$ in return for participation. Participants from Study 1 or 2 were excluded from participation. Of the sample, $41 \%$ were female. Ages ranged from $18-73$ years $(M=45$ years $)$. When asked about their 
highest qualification, $47 \%$ reported having GCSEs, A-levels or vocational qualifications, $35 \%$ of the sample had a higher education degree and $13 \%$ had completed a postgraduate qualification. Ninety-two percent of the sample was White-British. Forty-six percent were Christian and $42 \%$ were Atheist or Agnostic. Of those who identified with a religion, $25 \%$ indicated they practiced it.

\section{Design and procedure}

Each of the 16 fictitious characters was described with three key virtue features. The features were either central, peripheral, or marginal, based on the 'sum of ranks' metric. The 33 features with the lowest combined rank of frequency and centrality scores were considered central, the next 33 were considered peripheral, and the remaining 33 were deemed marginal. Features named once or twice in Study 1 constituted remote features. Selection of features for each condition was based on their relative location on the sum of ranks list and how well they could be combined with other features to make a realistic fictional character. Based on the principles of prototype analysis, the exact choice of features is fairly redundant, rather it is the level of centrality that is crucial to the responses and comparisons made. The valence of features in each character description was matched across the four conditions and a one-way ANOVA revealed no significant difference between them $(F(3,44)=.149, \mathrm{p}=.93)$.

Every participant was presented with all 16 fictional characters and, after reading each description, participants answered seven questions (see Figure 1). The key question linking the concept of virtue with cognitive processing of the character descriptions was 'How VIRTUOUS is this person?' Five items tapped well-established personality traits (questions 2 - 6) and the remaining question aimed to examine the correlation between the concepts of moral(ity) and virtue. Questions were answered on a Likert scale, from $1=$ not at all to $7=$ 
extremely. Each participant undertook all 16 trials i.e. all participants received all 16 character descriptions. The order of the trials and questions were randomized. The survey took an average of 21 minutes. ${ }^{10}$

\section{Results and Discussion}

We analysed responses to the question 'How VIRTUOUS is this person?' in terms of each of the four levels of centrality. A repeated measures ANOVA showed a significant difference in virtue rating between the four levels $\left(\mathrm{F}(3,282)=35.68, \mathrm{p}<.001, \eta_{\mathrm{p}}{ }^{2}=.255\right)$ and $\mathrm{a}$ significant linear trend $\left(\mathrm{F}(1,104)=72.89, \mathrm{p}<.001 \eta_{\mathrm{p}}^{2}=.412\right)$. Further planned analyses (using Bonferroni correction) revealed that although there was a significant difference across the four levels, results did not follow the pattern observed in a prototype analysis of gratitude (Morgan et al., 2014) or which Gregg and colleagues (2008) found for modesty. In both these studies, mean ratings significantly decreased between central and peripheral conditions; peripheral and marginal conditions; and marginal and remote conditions. In the current study however, means in the central condition were significantly different from marginal and remote ratings ( $\mathrm{p}<.001$, Cohen's $d=.505 ; \mathrm{p}<.001$, Cohen's $d=.511)$, but not from peripheral ratings $(\mathrm{p}=.193$, Cohen's $d=.069)$. We observed the anticipated decrease in rating from peripheral to marginal ( $\mathrm{p}<.001$, Cohen's $d=.460)$. However, we did not observe significantly different ratings between marginal and remote conditions (see Figure 2).

We conducted post-hoc tests to examine the difference in mean scores for individual character descriptions. Notably, there was a greater number of features sharing the same 'sum of ranks' in this study relative to the previous exploration of gratitude that informed Study $3 \mathrm{a}$

\footnotetext{
${ }^{10}$ The same participants took part in Studies $3 \mathrm{a}$ and $3 \mathrm{~b}$. This figure represents the average time taken to complete both studies.
} 
(from Morgan et al., 2014). This greater overlap in 'sum of ranks' scores could suggest a less obvious split between the four conditions for the concept of virtue. The final column in Table 1 shows the sum-of ranks metric increasing across the named features. Crucially however, the difference between the sum-of-ranks becomes less clearly delineated (as Table 1 shows) suggesting the metric may not distinguish clearly at the boundaries between the four conditions: central, peripheral, marginal and remote.

To examine whether some character descriptions were resulting in more extreme scores than others within the same condition, we examined mean scores for each individual character description (Persons A - P). A repeated measures ANOVA revealed a significant difference in mean ratings between the individual character descriptions $\left(\mathrm{F}(15,1560)=13.35, \mathrm{p}<.001, \eta_{\mathrm{p}}{ }^{2}\right.$ $=.114$ ). Further post-hoc analyses (using Bonferroni correction) compared differences between ratings for each character description, Persons A-P (see Figure 3).

Notably, Person E, depicting peripheral features of 'is charitable', 'is forgiving' and 'is pure', had the highest overall mean virtue rating $(\mathrm{M}=5.86)$. This is significantly higher than that of Person $\mathrm{A}^{11}(\mathrm{p}<.05$, Cohen's $d=.360)$, Person $\mathrm{B}^{12}(\mathrm{p}<.05$, Cohen's $d=.361)$ and Person $\mathrm{D}^{13}(\mathrm{p}<.001$, Cohen's $d=.385)$, all of which depict central features.

Within the peripheral condition, there were significant differences in rating between Person E and Person $\mathrm{F}^{14}, \mathrm{p}<.001$, Cohen's $\left.d=.449\right)$; between Person E and Person $\mathrm{H}^{15}, \mathrm{p}<.001$, Cohen's $d=.885)$; and between Person $\mathrm{G}^{16}$ and $\mathrm{H}(\mathrm{p}<.001$, Cohen's $d=.645)$. Thus, there was little consistency in virtue scores within the peripheral condition (see Figure 3). Post-hoc tests

\footnotetext{
${ }^{11}$ Person A: 'honest', 'has standards', 'thoughtful'.

${ }^{12}$ Person B: 'trustworthy', 'has integrity', 'conscientious'

${ }^{13}$ Person D: 'patient', 'loving', 'ethical'.

${ }^{14}$ Person F: 'positive', 'law-abiding', 'modest'

${ }^{15}$ Person H: 'friendly', 'happy', 'admirable'

16 Person G: 'sincere, 'has warmth', 'religious'
} 
indicate that the virtue scores for Person $\mathrm{E}$ and for Person $\mathrm{H}$ in particular, impacted on the overall difference between scores assigned to character descriptions depicting either central or peripheral features. In other words, the uncharacteristically high virtue rating ascribed to Person E and the atypically low ascription of virtue to Person H (both of which were made up of descriptors from the peripheral condition) deviate from the pattern of scoring one would have predicted.

Responses to 'How MORAL is this person?' showed a pattern closer to what one would anticipate for prototypical concepts. Descriptions containing central features were rated as more 'moral' than those comprised of peripheral features $(M=5.63$ and 5.51 respectively, $p<$ .05 , Cohen's $d=.191)$. Similarly, there was a significant decrease in 'moral' scores between peripheral and marginal conditions (mean difference $=.43, \mathrm{p}<.001$, Cohen's $d=.510$ ). There was no difference between marginal and remote conditions.

To explore responses to the question on virtue in more depth and to examine whether demographic variables impacted upon the findings, we conducted a mixed ANOVA with centrality (central, peripheral, marginal and remote) as the within-subjects variable and gender (female, male), age group (18 - 30 years; $31-45 ; 46-60$ and over 60$)$ and practice religion (yes, no) as between-subjects variables. The analysis revealed a main effect of centrality (as noted above) but no main effect of gender, age or practice religion. The results did demonstrate, however, a significant interaction between centrality, gender, and practice religion $(\mathrm{F}(3,129)$ $\left.=.772, \mathrm{p}<.05, \eta_{\mathrm{p}}^{2}=.086\right)$. The patterns across demographic groups were extremely varied and ultimately demonstrate that there is no standard way of responding to the person descriptions across conditions (see Figures in supplementary appendix).

We explored whether there was any relationship between participants' responses to 'How VIRTUOUS is this person' and the six other questions. A bivariate correlation revealed a large, 
positive correlation between virtuousness and moral $(\mathrm{r}=.80, \mathrm{p}<.001)$; virtuousness and openness $(\mathrm{r}=.59, \mathrm{p}<.001)$; virtuousness and conscientiousness $(\mathrm{r}=.70, \mathrm{p}<.001)$; and virtuousness and agreeableness $(r=.74, \mathrm{p}<.001)$. There was a medium negative correlation between virtuousness and neuroticism $(\mathrm{r}=-.34, \mathrm{p}<.001)$. There was no correlation with extroversion $(\mathrm{p}=.08, \mathrm{p}=.125)$. Thus, there was a strong similarity between how participants rated the character descriptions in terms of how virtuous they considered them and how moral, open, conscientious and agreeable they considered them, echoing earlier findings on the relationship of agreeableness and openness to morality (McCrae \& John, 1992).

Results from Study 3a did not corroborate the prototypicality of the concept of virtue. In particular, as we have seen, there was a lack of consistency in the virtue ratings assigned to the character descriptions in the peripheral condition (E, F, G and H). If these results are compared with those from a prototype analysis of gratitude (Morgan et al., 2014), it may have been easier for participants to aggregate an impression of a person description across more closely related gratitude words, than it was to assign a single Likert score across the three virtue words. Walker and Pitts (1998) noted the 'limited explanatory power' of single-word or brief-phrase descriptions 'in expressing the complex aspects of moral functioning, for example, conditionalities or relationships among attributes' (p. 415, our italics). This may have impacted on Study 3a, where three individual virtue features were clustered together to form each description. The combining of virtues into a character description may have affected how participants perceived and judged those persons overall. Participants may have perceived persons to be more (or less) virtuous than the sum of the three individual virtues.

\section{Study 3b}


Following Fehr (1988), Lapsley and Lasky (2001) and Lambert et al.., (2009), we conducted a recognition memory experiment to determine whether feature centrality affected recognition memory of features. Study $3 b$ therefore constituted an implicit task.

Participants were presented with 40 words and were asked whether each had been presented in the previous character descriptions. These 40 words consisted of 10 central and 10 peripheral features presented in the previous character description task, and 10 central and 10 peripheral features that had not been presented previously. If the concept of virtue is prototypically organized, central features that had not been presented would be 'falsely recognized' (inaccurately identified as having been presented in the character descriptions) more frequently than peripheral features that had not been presented previously. Recognition memory for features that had actually been presented would be similar for central and peripheral features.

\section{Method}

\section{Participants}

The same participants took part as in Study 3a.

\section{Design and procedure}

Ten central and ten peripheral features presented in Study 3a's character descriptions were selected. Additionally, ten central and ten peripheral features that were not presented in the character descriptions were chosen. Presented and non-presented central features were matched on centrality and valence scores, as were presented and non-presented peripheral features. Paired sample t-tests revealed no significant differences across presented and non-presented 
features in terms of centrality or valence. ${ }^{17}$

Participants were instructed:

"You will be presented with a list of words; some of these words you will have seen in the character descriptions in the last section of the questionnaire, and some of these words have not yet been presented. Thinking back to the character descriptions you have just seen, please decide which of the words listed below have been presented as part of the descriptions and which words have not."

Participants were presented with a word, for example 'Thoughtful', and prompted to select either 'Presented in character description' or 'NOT presented in character description'. Each participant responded to all 40 items. The order items were presented was randomised across participants.

\section{Results}

To determine whether feature centrality affected recognition memory, we compared false recognition of non-presented central features with non-presented peripheral features $(\mathrm{M}=3.62$ and $\mathrm{M}=2.82$ respectively), and recognition of presented central features with presented peripheral features $(M=3.78$ and $M=3.63$ respectively). A 2x2 repeated measures ANOVA revealed a significant main effect of presentation, whereby items that had been presented previously were more likely to be recognized by participants than those that had not $(M=3.70$

\footnotetext{
${ }^{17}$ Paired sample t-tests revealed: no significant difference between centrality scores across presented and nonpresented central features $(\mathrm{M}=6.31$ and 6.18 respectively, $\mathrm{t}(9)=1.56, \mathrm{p}=.15)$; no significant difference between valence scores across presented and non-presented central features $(\mathrm{M}=4.46$ and $4.53, \mathrm{t}(9)=-1.27, \mathrm{p}=$ .24); no significant difference between centrality scores across presented and non-presented peripheral features $(\mathrm{M}=5.49$ and $5.51, \mathrm{t}(9)=-.07, \mathrm{p}=.95)$; no significant difference between valence scores across presented and non-presented peripheral features $(\mathrm{M}=4.37$ and $4.24, \mathrm{t}(9)=.69, \mathrm{p}=.51)$.
} 
and $\mathrm{M}=3.22, \mathrm{~F}(1,104)=13.09, \mathrm{p}<.001)$. As per the hypothesized effects signposted in the Study $3 b$ description, there was no significant difference in overall recognition scores based on centrality of items $($ Central $\mathrm{M}=3.71$, Peripheral $\mathrm{M}=3.21, \mathrm{~F}(1,104)=1.46, \mathrm{p}=.23)$. Also in line with the hypothesized effects, there was a significant interaction between centrality and presentation whereby significantly more non-presented central features were falsely recognized compared with non-presented peripheral features $(\mathrm{F}(1,104)=4.91, \mathrm{p}=.03)$.

\section{Discussion}

In contrast to the explicit character description method of Study $3 \mathrm{a}$, the implicit recognition memory method of Study $3 \mathrm{~b}$ corroborated a prototypical structure by showing that feature centrality affected cognition of the concept of virtue. ${ }^{18}$ Therefore, findings from Study $3 \mathrm{~b}$ substantiated virtue's prototypical structure while results from Study 3a did not. What might account for these different conclusions? Studies 3a and b describe different kinds of task. Study 3a required participants to make explicit judgements about whether the three-word characters described in the person descriptions were 'virtuous' ${ }^{19}$ whereas Study $3 \mathrm{~b}$ was an implicit task that required participants to recognise whether they had/had not previously seen virtue features. One explanation for the divergent results could be that there is a 'lower threshold' for recognising a given word as virtuous than there is for making a considered decision about whether a person is virtuous, based on three descriptors alone.

While the person descriptor method of Study 3a corroborated prototypicality of gratitude (Morgan et al, 2014) it may yield a less reliable pattern where the concept under scrutiny is broader and associated with a larger number of features. Morgan et al. (2014) reported 63 key

\footnotetext{
${ }^{18}$ It should be acknowledged that only two categories (central and peripheral) were compared here, as opposed to central, peripheral, marginal and remote categories in Study 3 a.

${ }^{19}$ And moral, open, conscientious, extroverted, agreeable and neurotic
} 
features of gratitude, while Gregg et al. (2008) reported 48 key modesty features - half as many as were found for the concept of virtue in the present study (99). Participants' varying judgements about whether the features (both individually and collectively) are deemed characteristic of a virtuous person are more likely to operate in the explicit person description task than in the implicit recognition task. Walker and Pitts' (1998) point about 'relationships among attributes' is also pertinent; persons may be deemed more (or less) virtuous than the sum of the three individual 'parts' in Study 3a.

\section{General Discussion}

The current study does not demonstrate conclusively whether the concept of virtue is prototypically organised, though it should be noted that Lapsley and Lasky (2001) also reached different conclusions with the two methods they used to attempt to corroborate the prototypicality of 'good character' (recognition memory and recall memory). Therefore, the discrepant findings in this study are by no means unprecedented. A review of all methods of assessing prototypicality, (implicit and explicit) is needed to shed light on those methods which report relatively consistent findings and those which have been mixed, since whether prototypicality of a given concept is corroborated may in fact be heavily influenced by the method selected.

In the course of examining whether the concept of virtue is prototypically organised, the current study has brought to light discrepancies between features that laypeople spontaneously associate with virtue in a free-listing task and the human excellences that make up the VIA-IS - the dominant virtue classification currently in use. In Study 1's free-listing, participants named general features of virtue such as 'good/goodness' and 'moral/morality' as well as prototypical virtues such as 'honesty' and 'kindness'. However, the distinctive VIA character 
strengths of 'creativity', 'curiosity', 'judgement', 'love of learning', 'perspective', 'zest', 'social intelligence', 'teamwork', and 'leadership', deemed 'distinguishable routes' to the virtues of wisdom, courage, humanity and justice respectively, did not feature in participants' free-listing of features associated with virtue, which one might have expected if laypeople see these strengths as being typical examples ('exemplifications') of higher-order categories of virtues as is presupposed by the VIA-IS.

Ruch and Proyer (2015) took the existence and organisational structure of the character strengths and virtues of the VIA-IS as read. As such, their approach is far more likely to affirm the VIA classification, even if individuals assign strengths to different virtues than those originally presupposed by the classification. The same is true of factor analyses of the VIA-IS (for example McGrath, 2015; McGrath \& Walker, 2016; McGrath, Greenberg and HallSimmonds, 2018), which set out from the position of broad acceptance of the classification (though with grounds for excluding strengths if they do not load onto the higher order virtue categories/factors). Both approaches therefore give initial assent to the classification which they then test in their different ways.

In contrast, by adopting a free-listing approach, the current study starts out from a 'neutral' position and offers a first step towards defining the concept of virtue (and prototypical instantiations of virtues) from a lay perspective. This study highlights some incongruities between 'specialists" understanding of strengths and virtues, and non-expert views.

In this connection, it will be recalled that in Study 1 no participants in our lay sample named 'humanity', 'temperance' or 'transcendence' as features of virtue, though one could reasonably expect at least some 'experts' (philosophers or psychologists) to have done so. This raises the question of whether to some extent, these more specialist virtue terms have limited utility in the general population. Indeed, this may be true of the concept of 'virtue' more broadly, which 
may represent a concept which is perhaps not widely used by laypeople in everyday contexts. Replication across diverse populations and cultures would be necessary to examine this further. For instance, might there be fewer discrepancies between older laypeople and specialists than between younger laypeople and specialists, or between participants' with different educational backgrounds? Might there be substantial differences in identifying features of virtue within the 'specialist' category itself - for instance between philosophers and (positive) psychologists?

These current findings are based on a UK-only population, however, prototype analyses have been used to identify cross-cultural similarities and differences in how a construct is understood (e.g., Fehr, 1988; Morgan et al., 2014). Therefore, future research could utilise a similar prototype approach to examine the extent to which virtues are universally recognised. However, it should be noted that, whilst prototype analyses offer an important insight into conceptions of a construct, a deeper understanding of conceptualisations of virtue might be gleaned through in-depth qualitative interviews or studies of moral exemplars embodying these excellences of character (Colby \& Damon, 1992; Damon \& Colby, 2015).

To conclude, the question of how the general public spontaneously understand the concept of virtue is under-scrutinized. The current study attempts to address this and throws into relief some incongruities between the human excellences of the VIA classification and the features laypeople instinctively associate with virtue. What is proposed here is a 'paradigm shift' away from research that uses the VIA classification as the basis for testing understandings of virtue (top down), to a bottom-up approach where laypeople' spontaneous understanding of the concept of virtue is tapped. In-depth interviews of and discussions with laypeople about moral exemplars promote deeper understanding of conceptualisations of virtue, extending the prototype methodology used here. 
The findings of this study have implications for self-report virtue measures, such as the VIAIS character strengths survey, in terms of the provision of clear definitions and direction to participants. The current results could also offer guidance with regard to modifying existing measures and classifications to better reflect lay interpretations; in line with the aforementioned 'paradigm shift', a measurement tool that is built in conjunction with lay people's conceptions might allow for a more coordinated and harmonized framework for assessing virtue concepts. In the absence of such a contribution, we risk perpetuating conceiving and measuring human excellences in ways that 'construct' character strengths in line with a model which may not ultimately reflect what ordinary people really think virtue is. 


\section{References}

Annas, J. (2011). Intelligent virtue, Oxford: Oxford University Press.

Brokken, F.B. (1978). The language of personality. Meppel, The Netherlands: Krips.

Cawley, M.I, Martin, J.E. \& Johnson, J.A. (2000). A virtues approach to personality. Personality and Individual Differences, 28, 997 - 1013.

Colby \& Damon. (1992). Some do care: Contemporary lives of moral commitment. New York: Free Press.

Damon, W. \& Colby, A. (2015). The Power of Ideals: The Real Story of Moral Choice. Oxford: Oxford University Press.

Fehr, B., \& Russell, J.A. (1984). Concept of emotion viewed from a prototype perspective. Journal of Experimental Psychology, 113 (3), 464-486.

Fehr, B. (1988). Prototype analysis of the concepts of love and commitment. Journal of Personality and Social Psychology, 55 (4), 557-579.

Fowers, B. (2005). Virtue and Psychology: Pursuing Excellence in Ordinary Practices. Washington, DC: American Psychological Association.

Gregg, A.P., Hart, C. M., Sedikes, C., \& Kumashiro, M. (2008). Everyday conceptions of modesty: A prototype analysis. Personality and Social Psychology Bulletin 34 (7), 978-992.

Hardy, S.A., Walker, L.J., Olsen, J.A., Skalski, J.E. \& Basinger, J.C.(2011). Adolescent naturalistic conceptions of moral maturity. Social Development, 20 (3), 562-586.

Kearns, J.N., \& Fincham, F.D. (2004). A prototype analysis of forgiveness. Personality and Social Psychology Bulletin 30 (7), 838-855.

Kesebir, P. \& Kesebir, S. (2012). The cultural salience of moral character and virtue declined in twentieth century America. Journal of Positive Psychology, 7(6), 471-480.

Kristjánsson, K. (2015). Aristotelian character education, Oxford: Routledge. 
Lambert, N.M., Graham, S.M. \& Fincham, F.D. (2009). A prototype analysis of gratitude: Varieties of gratitude experiences. Personality and Social Psychology Bulletin, 35 (9), 1193-1207.

Lapsley, D.K. \& Lasky, B. (2001). Prototypic moral character. Identity: An International Journal of Theory and Research, 1 (4), 345-363.

MacIntyre, A. (1981). After virtue: A study in moral theory. Notre Dame, IN: University of Notre Dame Press.

McCrae, R. R., \& John, O. P. (1992). An introduction to the five-factor model and its applications. Journal of Personality, 60, 175-215.

McGrath, R. E. (2015). Integrating psychological and cultural perspectives on virtue: The hierarchical structure of character strengths. Journal of Positive Psychology, 10, 407-424.

McGrath, R.E. (2015). Integrating psychological and cultural perspectives on virtue: The hierarchical structure of character strengths. Journal of Positive Psychology, 10, 407 - 424.

McGrath, R.E., Greenberg, M.J. \& Hall-Simmonds, A. (2018). Scarecrow, tin woodsman, and cowardly lion: The three-factor model of virtue. Journal of Positive Psychology, 13, $373-392$.

McGrath, R. E., \& Walker, D. I. (2016). Factor structure of character strengths in youth: Consistency across ages and measures. Journal of Moral Education, 45(4), 400-418.

Morgan, B., Gulliford, L. \& Kristjánsson, K. (2014). Gratitude in the UK: A new prototype analysis and cross-cultural comparison. Journal of Positive Psychology, 9, 281- 284.

Peterson, C. \& Seligman, M.E.P. (2004). Character strengths and virtues: A handbook and classification. Oxford: Oxford University Press. 
Rosch, E. (1977). Human categorization. In E. Rosch \& B.B. Lloyd (Eds.), Cognition and categorization (pp. 27-71). Hillsdale, NJ: Erlbaum.

Ruch, W. \& Proyer, R.T (2015). Mapping strengths into virtues: the relation of the 24 VIAstrengths to six ubiquitous virtues. Frontiers in Psychology, 6, Article 460, 1-12.

Rosenberg, S. \& Sedlak, A. (1972). Structural representations of implicit personality theory. Advances in Experimental Social Psychology, 6, 235-297.

Rosenthal, R. (1979). The 'file drawer problem' and tolerance for null results. Psychological Bulletin, 86 (3), 638-641.

Vauclair, C-M., Wilson, M. \& Fischer, R. (2014). Cultural conceptions of morality: Examining laypeople's associations of moral character. Journal of Moral Education, 43 (1), 54-74.

Walker, L.J. \& Pitts, R.C. (1998). Naturalistic conceptions of moral maturity. Developmental Psychology, 34 (3), 403-419. 